\title{
Alternatif Akımsız Ni-B-P Kaplamaların Morfolojisi ve Aşınma Banyo Sıcaklığının Özelliklerine Etkisi
}

\author{
${ }^{1}$ Mehmet Uysal \\ ${ }^{*}$ Mühendislik Fakültesi, Metalurji ve Malzeme Mühendisliği, Sakarya Üniversitesi, Sakarya, 54187, Türkiye \\ *mehmetu@sakarya.edu.tr
}

\section{Özet}

Elektrolitik kaplamalara alternatif ve elektrik ihtiyacına gerek duymadan otokatalitik olarak akımsız kaplamalar geniş kullanım alanına sahiptir. Akımsız Ni kaplamalar, düşük birikim maliyeti, karmaşık şekilleri kaplama, yüksek sertlik, yüksek aşınma direnci ve iyi korozyon özellikleri nedeniyle otomotiv, havacılık ve elektronik ürünlerinde sert bir tribolojik kaplama olarak popüler hale gelmiştir. Literatürde, üstün korozyon özelliklerinden dolayı Nikel-fosfor kaplamalar tercih edilirken, nikel-bor kaplamalar yüksek aşınma direnci özelliklerinden dolayı tercih edilmektedir. Bu çalışmada, Ni-B-P kaplamaların morfoloji, sertlik ve aşınma özellikleri üzerine kaplama banyosu sıcaklığın etkisi incelenmiştir.

Anahtar Kelimeler: Akımsız kaplamalar, banyo sıcaklığı, alüminyum altık, alaşım kaplama.

\begin{abstract}
As alternative to electrolytic coatings, autocatalitic electroless coating which no need electricity have a wide range of use. Electroless $\mathrm{Ni}$ coatings became popular as a hard tribological coating in automotive, aerospace and electronic products because of its low deposition cost, ability to coat complex shapes, high hardness, high wear resistance and good corrosion properties. In the literature, Nickel-phosphorus coatings are preferred due to their superior corrosion properties while nickel-boron coatings are preferred due to their high wear resistance properties. In this study, the effect of coating bath temperature on the morphology, hardness and wear characteristics of Ni-B-P coatings was investigated.
\end{abstract}

Keywords: Electroless coating, bath temperature, aluminium substrate, alloy coating

\section{Giriș}

Elektriksel kaplamaya alternatif olarak dışarıdan herhangi bir elektrik ihtiyacına gerek duymadan yapılan otokatalitik akımsız kaplamalar pek çok endüstriyel alanda kullanılmaktadır. Yüksek sertlik, kompleks şekilli parçaların dahi homojen bir kalınlıkta kaplanması, iyi aşınma ve korozyon direncine sahip olması, akımsız kaplamaları avantajlı hale getirmektedir. Akımsız kaplamalarda ayrıca yağlayıcılık, süneklik, elektriksel ve manyetik özellikler gibi avantajlar sağlanmaktadır [1-5]. İlk nikel kaplamaları bulan kişi Brenner ve arkadaşlarıdır [1]. Buradaki

*Corresponding author: Mehmet Uysal Address: Mühendislik Fakültesi, Metalurji ve Malzeme Mühendisliği, Sakarya Üniversitesi, 54187, Sakarya TURKEY. E-mail address: mehmetu@sakarya.edu.tr, Phone: +90555422435 
olay kimyasal indirgeyiciyle bir metal bileşiğinin bir malzeme üzerine nötr metal şeklinde kaplanmasıdır. $1845^{\prime}$ te Wurtz, nikel tuzu çözeltilerinden, hipofosfit ile indirgeme yaparak metalik nikeli toz halinde elde etti. İlk defa Brenner ve Ridder 1946 yılında, iki yılı aşan bir çalışmadan sonra hiposfit bazlı akımsız bir nikel kaplama metodunu hayata geçirdiler [1]. Bu yöntem belirli yüzeylerin katalitik aktivasyonuna göre istenilen nikel kaplamasını mümkün kıldı. Daha sonraki zamanlarda birçok metot geliştirildi. 1952 yılında Kanigen metodu, 1965'te “Borhidrür yöntemleri” ismiyle anılan yöntemler geliştirildi. 1967'den itibaren çok fazla gelişen ve artan kullanım alanlarıyla büyüyen bir pazar alanı oluştu [1]. İlk akımsız kaplama uygulamaları nikel ve kobalt alaşımlarının kaplanmasıyla başlanmış olup, günümüzde bakır, altın, gümüş, ve paladyum gibi metaller de biriktirilmektedir. Ancak en yaygın uygulanan kaplama metali nikeldir. Akımsız yöntemin lehimleme uygulamaları için de uygun olduğu görülmüştür $[5,6]$.

Akımsız nikel kaplama kimyasal redüksiyonla çözeltideki nikel iyonlarının metalik nikele indirgenmesini sağlayan kimyasal bir işlemdir [4]. Akımsız nikel kaplamalar üç ana gruba ayrılabilir. Bunlar nikel-fosfor kaplamalar, nikel-bor kaplamalar ve saf nikel kaplamalardır [7]. Kimyasal redüksiyonu Ni-P kaplamalar için sağlayan sodyum hipofosfit, Ni-B kaplamalar için sodyum borhidrür ve dimetilamino boran (DMAB) bileşiği sıklıkla kullanılan indirgeyicilerdir.

Bunun dışında akımsız kaplama metodu, alaşımlı kaplamaların üretilmesi için de çok kullanılır. Üçlü ve dörtlü alaşımlar literatürde çoklu alaşımlar olarak geçmektedir [8]. Bazı Ni-Co-P, Ni-Fe$\mathrm{P}$ ve Ni-Co-Fe-P gibi çoklu alaşımlar üstün manyetik özelliklerinden dolayı yaygın olarak kullanılmaktadır. Molibden içeren üçlü alaşım (Ni-Mo-B) sistemleri iyi lehimlenebilirliğe sahiptir (\%17 Mo, \%0,3 B) ve ferromanyetizması özelliğinden dolayı da elektronik endüstrisinde kullanabilir olmasını sağlar. Tungsten $(\% 10 \mathrm{~W})$ içeren üçlü alaşımlar, kaplamanın sertlik ve korozyon direncinde bir artış sağlamaktadır. Ağırlıkça \%40'a kadar kalay (Sn) içeren alaşımlar ise iyi korozyon direncine sahip malzemeler olarak kabul edilir. Genellikle çok alaşımlı kaplamalar, eşsiz kimyasal ve yüksek sıcaklık direnci veya elektriksel, manyetik veya manyetik olmayan özelliklerin gerekli olduğu uygulama alanlarına kullanılırlar. İstenilen fiziksel ve mekanik uygulamalar için farklı alaşımlar kaplanır ve alaşımın seçimi, uygulamalara ve ekonomik hususlara bağlıdır. Hipofosfit ile indirgenmiş akımsız Ni-P kaplama prosesi, düşük maliyeti, kontrol kolaylığı ve iyi korozyon direnci sunma özelliği nedeniyle tercih edilmektedir. Akımsız Ni-B kaplamaların tribolojik özellikleri, Ni-P kaplamalardan genellikle daha üstündür. Akımsız Ni-B kaplamalar takım çeliğinden ve sert krom kaplamalara kıyasla aşınmaya daha dirençlidir ve elektronik endüstrisinde altının yerini alabilir. Ni-B kaplamaların sütun yapısı, aşındırıcı koşullar altında çalışan parçalar için yağlayıcıların tutulmasında ve aşınmayı azaltmada fayda sağlayan bir morfolojik üstünlüğe sahiptir [2, 6, 9].

Bu çalışmada akımsız alaşım kaplama olan Ni-B-P kaplamaların oluşturulması ve morfolojisine banyo sıcaklığının etkisi incelenmiş olup, aşınma özellikleri üzerine etkisi de tartışılmıştır.

\section{Malzeme ve Method}

Deneysel çalışmalarda altlık malzeme olarak $50 \mathrm{~mm} \times 30 \mathrm{~mm} \times 2 \mathrm{~mm}$ boyutlarında 6061 serisi alüminyum plakalar kullanılmıştır. Kaplama yapılmadan önce altlıklar sırasıyla 120, 240, 400, 
600, 800, 1000 ve 1200'lük SiC zımparalarla zımparalandıktan sonra yüzeyleri parlatılmıştır. Daha sonra asidik bir banyo içerisinde yüzeyinde bulunabilecek yağ, kir ve oksit tabakası giderilmiştir. Malzeme yüzey kirliliklerinin giderilmesi için ön temizleme işlemi uygulanmış numuneler, $\mathrm{NiSO}_{4}$ içeren ticari zinkat banyosuna daldırılmıştır. Yüzey temizlemeden kaplamaya kadar tüm gerçekleştirilen işlem adımları sırasıyla şöyledir:

Asidik temizleme (10ml/1 sülfürik asit, $12.5 \mathrm{ml} / 1$ hidroflorik asit, 25ml/1 nitrik asit), durulama (saf su ile), zinkatlama işlemi (Ticari zinkat kullanılmıştır), akımsız Nikel-Bor-Fosfor kaplama (Ni-B$\mathrm{P})$, tüp firında 1 sıl işlem $\left(400^{\circ} \mathrm{C}\right.$ sıcaklıkta 2 saat süreyle $\mathrm{Ar}-\% 5 \mathrm{H}_{2}$ gazı atmosferinde) ve oda sicaklığına soğutma.

Taramalı elektron mikroskobu (SEM) yardımıyla kaplama tabakasının yüzey görüntüleri alınarak 1sıl işlem öncesi ve sonrası kaplama tabakasında meydana gelen değişimler tespit edilmiştir. EDS ile kaplamalarda elementel fosfor da analiz edilerek morfolojideki dağılımı da tespit edilmiştir. Kaplama tabakasının bileşimi ve ısıl işlem sonucu kaplama tabakasında meydana gelen faz değişimleri Rigaku D/MAX 2000 marka XRD cihazı ile belirlenmiştir. X-1şınları analizi bakır tüp $\left(\lambda=1,5418\right.$ A) kullanılarak gerçekleştirilmiştir. X-ışınları taraması $10^{\circ}$ ile $90^{\circ}$ arasında $2 \%$ dk'l1k hızla gerçekleştirilmiştir. Isıl işlem görmemiş numunelerle 1sıl işlem görmüş bütün numunelerin XRD paternleri alınarak yapıdaki değişimler incelenmiş, 1sıl işlem sonrası yapıdaki $\mathrm{Ni}_{3} \mathrm{P}$ vb. bileşiklerinin oluşup oluşmadığı tespit edilmiştir. Akımsız kaplama sonrası farklı numuneler için mikrosertlik değerleri Leica VMHT marka cihazla ölçülmüsştür. 25 gr'lık yükler uygulanarak bir numuneye en az 5 ölçüm yapılmış ve ortalamaları Vickers sertlik değeri olarak alınmıştır. Isıl işlem görmüş numuneler ile görmemiş numunelerin sertlik değerlerindeki farklılıklar tespit edilmiştir.

\section{Deneysel Sonuçlar ve Tartışma}

Akımsız Ni-B-P kaplama çalışmalarında çok sayıda banyo bileşimi hazırlanmış olup kullanılan kimyasalların saflığı yüksek kaliteli olarak seçilmiştir. Çözeltilerin hazırlanmasında iki kere damıtılmış saf su kullanılmıştır. Bu tür çalışmalarda banyo $\mathrm{pH}$ ’1 çok önem arz ettiğinden, kaplama esnasında sürekli sıcaklık ve pH ölçümü yapılmıştır. Kaplama süresince pH değeri $\mathrm{NaOH}$ ilavesi ile 5-6 arasında tutulmaya çalışılmıştır. Kaplama süresi olarak tüm banyolarda 60 dakika seçilmiştir. Kaplama sırasında banyonun sıcaklığı parametre olarak incelenmiştir. Akımsız Ni-B-P kaplanmış numunelere tav fırınında $400^{\circ} \mathrm{C}$ sıcaklıkta 2 saat süreyle argon-hidrojen atmosferinde 1sıl işlem uygulanmıştır. Isıl işlem sonrası numuneler oda sıcaklığına soğuyuncaya kadar bekletilmiştir. Banyo bileşimi olarak nikel kaynağı nikel sülfat, kompleks yapıcı olarak sodyum asetat ve laktik asit ( $\mathrm{pH}$ düzenleyici) kullanılmıştır. Tioüre banyonun çökmesini önlemek

amacıyla kullanılmıştır. Bor kaynağı ve indirgeyici olarak DMAB, fosfor kaynağı ve indirgeyici olarak sodyum hipofosfit kullanılmıştır.

Akımsız Ni-B-P kaplamaların üretilmesi amacıyla kullanılan banyo bileşimi ve parametrelerin neler olduğu Tablo 1 de, $70-95^{\circ} \mathrm{C}$ lerde elde edilen kaplamalara ait SEM görüntüleri ise Şekil 1 a, b, c, d, e ve f de verilmiştir. 
Tablo 1. Akımsız Ni-B-P kaplamaların banyo bileşimi

\begin{tabular}{lllllll}
\hline Banyo Bileşenleri & NiBP70 & NiBP75 & NiBP80 & NiBP85 & NiBP90 & NiBP95 \\
\hline Nikel Sülfat & $33 \mathrm{~g} / \mathrm{L}$ & $33 \mathrm{~g} / \mathrm{L}$ & $33 \mathrm{~g} / \mathrm{L}$ & $33 \mathrm{~g} / \mathrm{L}$ & $33 \mathrm{~g} / \mathrm{L}$ & $33 \mathrm{~g} / \mathrm{L}$ \\
Sodyum hipofosfit & $20 \mathrm{~g} / \mathrm{L}$ & $20 \mathrm{~g} / \mathrm{L}$ & $20 \mathrm{~g} / \mathrm{L}$ & $20 \mathrm{~g} / \mathrm{L}$ & $20 \mathrm{~g} / \mathrm{L}$ & $20 \mathrm{~g} / \mathrm{L}$ \\
Sodyum Asetat & $16 \mathrm{~g} / \mathrm{L}$ & $16 \mathrm{~g} / \mathrm{L}$ & $16 \mathrm{~g} / \mathrm{L}$ & $16 \mathrm{~g} / \mathrm{L}$ & $16 \mathrm{~g} / \mathrm{L}$ & $16 \mathrm{~g} / \mathrm{L}$ \\
Laktik Asit & $28 \mathrm{ml} / \mathrm{L}$ & $28 \mathrm{ml} / \mathrm{L}$ & $28 \mathrm{ml} / \mathrm{L}$ & $28 \mathrm{ml} / \mathrm{L}$ & $28 \mathrm{ml} / \mathrm{L}$ & $28 \mathrm{ml} / \mathrm{L}$ \\
DMAB & $2 \mathrm{~g} / \mathrm{L}$ & $2 \mathrm{~g} / \mathrm{L}$ & $2 \mathrm{~g} / \mathrm{L}$ & $2 \mathrm{~g} / \mathrm{L}$ & $2 \mathrm{~g} / \mathrm{L}$ & $2 \mathrm{~g} / \mathrm{L}$ \\
Tioüre & $0,001 \mathrm{~g} / \mathrm{L}$ & $0,001 \mathrm{~g} / \mathrm{L}$ & $0,001 \mathrm{~g} / \mathrm{L}$ & $0,001 \mathrm{~g} / \mathrm{L}$ & $0,001 \mathrm{~g} / \mathrm{L}$ & $0,001 \mathrm{~g} / \mathrm{L}$ \\
SDS & $0,1 \mathrm{~g} / \mathrm{L}$ & $0,1 \mathrm{~g} / \mathrm{L}$ & $0,1 \mathrm{~g} / \mathrm{L}$ & $0,1 \mathrm{~g} / \mathrm{L}$ & $0,1 \mathrm{~g} / \mathrm{L}$ & $0,1 \mathrm{~g} / \mathrm{L}$ \\
$\mathbf{p H}$ & $5-6$ & $5-6$ & $5-6$ & $5-6$ & $5-6$ & $5-6$ \\
$\mathbf{t}(\mathbf{d k})$ & 60 & 60 & 60 & 60 & 60 & 60 \\
$\boldsymbol{T}\left({ }^{\circ} \boldsymbol{C}\right)$ & $\mathbf{7 0}$ & $\mathbf{7 5}$ & $\mathbf{8 0}$ & $\mathbf{8 5}$ & $\mathbf{9 0}$ & $\mathbf{9 5}$ \\
\hline
\end{tabular}
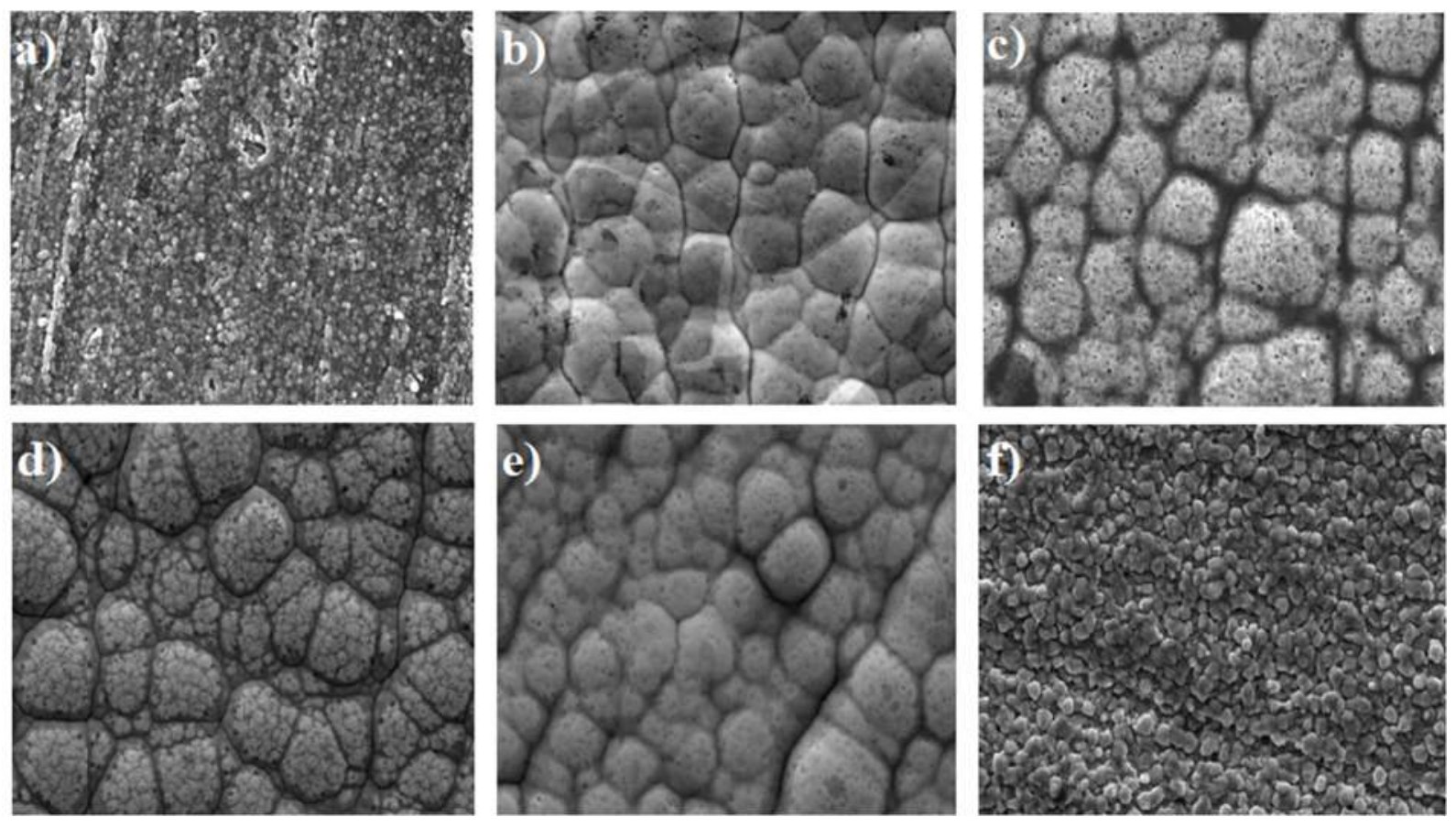

Şekil 1. Akımsız Ni-B-P kaplamaların sıcaklık etkisinin SEM görüntüsü (a) NiBP70, (b) NiBP75, (c) NiBP80, (d) NiBP85 e) NiBP90 (f) NiBP95 
Şekil 1 den görüldüğü gibi çalışmalar $70^{\circ} \mathrm{C}$ 'den $95^{\circ} \mathrm{C}^{\prime}$ ye kadar beşer derece farkla yapılmıştır. $70^{\circ} \mathrm{C}$ ' de sicaklık yeterli olmadığından dolayı $\mathrm{Ni}_{2} \mathrm{~B}, \mathrm{Ni}_{3} \mathrm{~B}, \mathrm{Ni}_{2} \mathrm{P}$ ve $\mathrm{Ni}_{3} \mathrm{P}$ yapılarının oluşumu tamamlanmamıştır. Bu nedenle de ince bir kaplama gerçekleşmiş olup bu kaplamanın kalınlığ Şekil 2a'da görülmektedir. $70^{\circ} \mathrm{C}^{\prime}$ den sonra ise sırasıyla $\mathrm{Ni}-\mathrm{B}$ ve $\mathrm{Ni}-\mathrm{P}$ yüzey morfolojilerine tekabül eden karnabahar-granül yapısının karakteristik karışımı ile nispeten üniform ve stabil bir Ni-B-P birikimi (Şekil 1 e-f) elde edilmiştir. Sıcaklığın artmasıyla birlikte tane sınırları da daha belirgin hale gelmiştir. Ancak 90-95 ${ }^{\circ} \mathrm{C}$ 'lerde yapının tamamiyle değiştiği ve kısmen amorflaşıp tane sınırlarının azaldığı da görülmektedir. 70 derecede granüler haldeki tanelerin en son dereceye çıkıldığında kübik bir yapıya dönüştügüü, düşük sıcaklıkta oluşan yapıların artan sıcaklıkla yeni fazların oluşumunu tetiklediği XRD sonuçlarına bakıldığında (Şekil 3) gözlenmektedir.
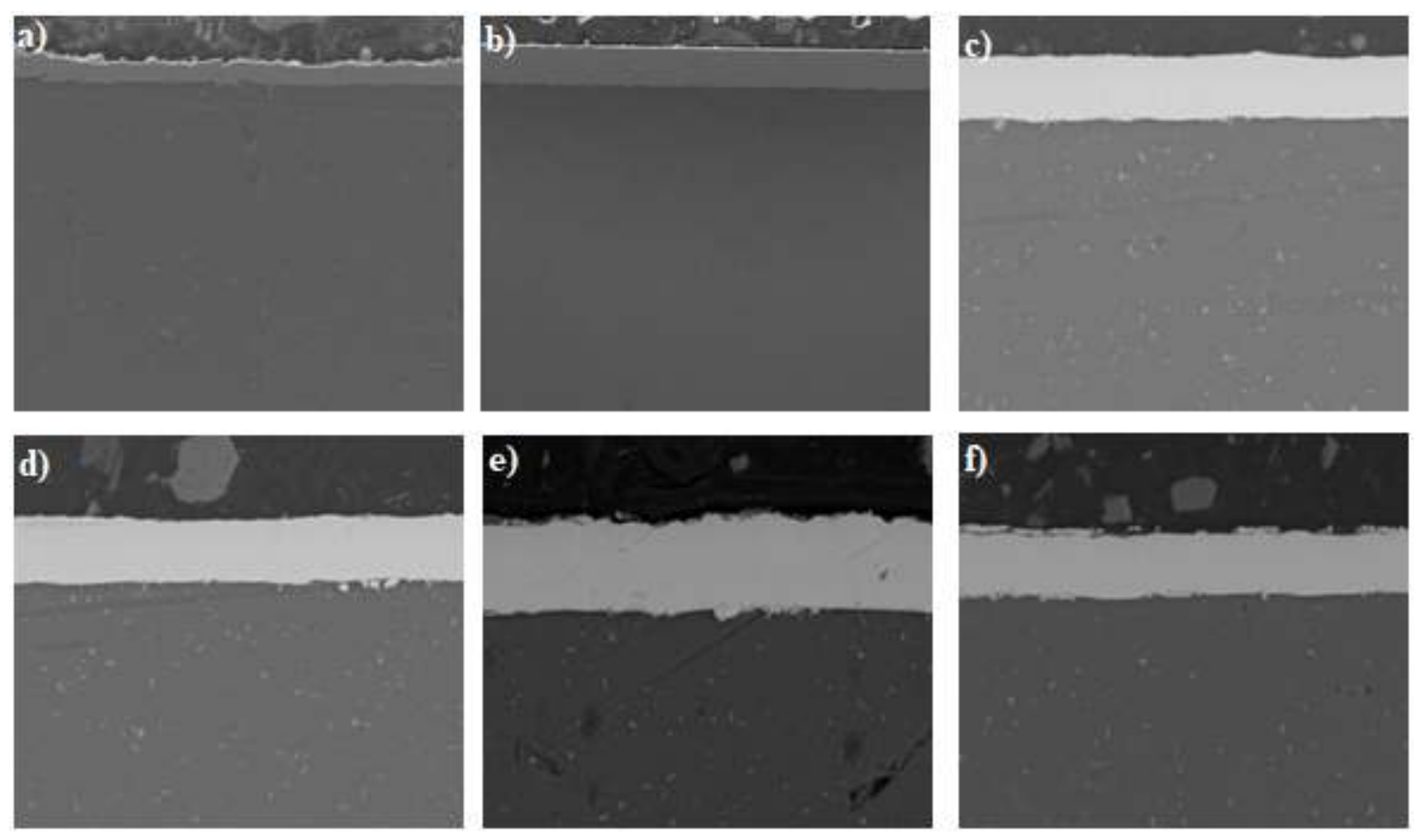

Şekil 2. Akımsız Ni-B-P kaplamaların sıcaklık etkisinin kesit görüntüsü (a) NiBP70, (b) NiBP75, (c) NiBP80, (d) NiBP85 e) NiBP90 (f) NiBP95

Şekil 2.'de yukarıda SEM görüntüleri verilen numunelerin kesit görüntüleri görülmektedir. Burada sıcaklık artışıyla birlikte kesitlerin mikron mertebesinde arttığ gözlenmektedir. En iyi ve homojen kesit görüntüsü $85^{\circ} \mathrm{C}$ 'de elde edilmektedir. $90^{\circ} \mathrm{C}$ ve $95^{\circ} \mathrm{C}$ 'de ise kesitte kalınlık artmasına rağmen yüzeyinde ve arakesitte pürüzlülük ile kaplama iç yapısında gözenekler göze çarpmaktadır. $95^{\circ} \mathrm{C}$ 'de artan pürüzlülük yanında yüzeyde görülen homojensizliğin sebebinin yapının değişimiyle alakalı olabileceği kanısına varılmıştır [9, 10].

Şekil 3'de kaplama tabakasının bileşimini ve ısıl işlem sonucu kaplama tabakasında meydana gelen faz değişimlerini tespit etmek için XRD paternleri alınmıştır. Isıl işlem görmüş bütün numunelerin XRD paternleri alınarak yapıdaki değişimler incelenmiş, 1sıl işlem sonrası yapıdaki 
$\mathrm{Ni}_{2} \mathrm{~B}, \mathrm{Ni}_{3} \mathrm{~B}, \mathrm{Ni}_{2} \mathrm{P}$ ve $\mathrm{Ni}_{3} \mathrm{P}$ bileşiklerinin oluşup oluşmadığ tespit edilmiştir. Burada $70^{\circ} \mathrm{C}$ 'de nikel ve $\mathrm{Ni}_{3} \mathrm{P}$ fazları oluşur iken, sıcaklık arttıkça borlu ve fosforlu bileşikler meydana gelmiştir. $80^{\circ} \mathrm{C}$ ve sonrasinda $40-42^{\circ}$ ve $50-52^{\circ}$ ' de $\mathrm{Ni}_{3} \mathrm{P}, 44$ ve $78^{\circ}$ ' de Nikel, $46^{\circ}$ ' de $\mathrm{Ni}_{2} \mathrm{P}, 48^{\circ}$ ' de $\mathrm{Ni} 33,55^{\circ}$ 'de $\mathrm{Ni}_{2} \mathrm{~B}$ fazları oluşmaktadır. Sıcaklık artışıyla birlikte piklerin şiddetleri artmaktadır ve bordan ziyade fosforlu bileşiklerin oranı artmaktadır. $95^{\circ} \mathrm{C}$ 'de ise yapı tamamıyla değişmiş olup nikel, $\mathrm{Ni}_{3} \mathrm{P}, \mathrm{Ni}_{3} \mathrm{~B}$ ve $\mathrm{Ni}_{2} \mathrm{~S}$ yapısı oluşmaktadır. Banyo bileşimde kullanılan tioüre varlığ $95^{\circ} \mathrm{C}^{\prime} \mathrm{de} \mathrm{Ni}_{2} \mathrm{~S}$ yapısının oluşuma da neden olmuştur. Nikel ve tioüredeki sülfür iyonlarının kaplamada yeni bir sülfürlü bileşik oluşturduğunu literatür de desteklenmektedir [11-13].

XRD sonucu piklerin kristal büyüklüğü ise Scherrer's formülasyonuna göre hesaplanır:

$\mathrm{D}=0.9 \gamma \div(\beta \cos \Theta)$

Burada; D kristal büyüklüğü, $\lambda$ X-1şınımı dalga boyu, $\theta$ Bragg açısı ve $\beta$ FWHM yani pikin yarısındaki maksimum genişliktir.

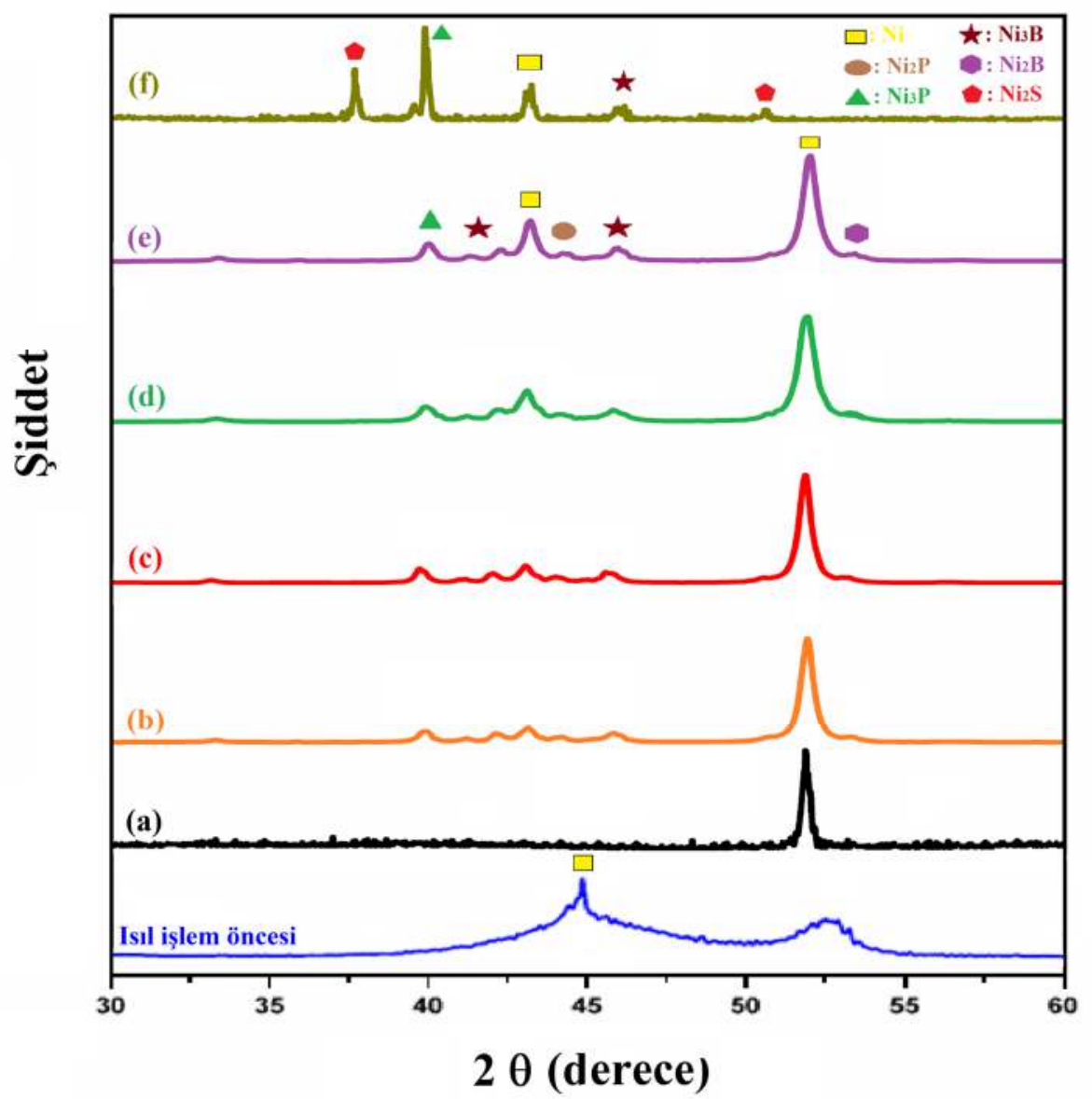

Şekil 3. Akımsız Ni-B-P kaplamaların sıcaklık etkisinin ısıl işlem sonrası XRD görüntüsü (a) NiBP70, (b) NiBP75, (c) NiBP80, (d) NiBP85 e) NiBP90 (f) NiBP95 
Farklı sıcaklıklarda akımsız kaplanmış numunelerin mikrosertlik değerleri Leica VMHT marka cihazla ölçülmüştür. 25 gr'lık yükler uygulanarak bir numuneye en az 5 ölçüm yapılmış ve ortalamaları Vickers sertlik değeri olarak alınmıştır. Isıl işlem görmemiş numuneler ile 1sıl işlem görmüş numunelerin sertlik değerlerindeki farklılıklar tespit edilmiştir. Şekil 4'de numunelerin sertlikleri HV olarak verilmiştir. Burada en iyi sertlik 85 ve $90^{\circ} \mathrm{C}$ 'de elde edilmiştir. $95{ }^{\circ} \mathrm{C}$ 'de sertliğin düşmesinin sebebi ise yapının değişmesiyle birlikte 1 sıl işlem ve sonrasında amorf/yarı amorf yapıya dönüşümün fazlaca olmasındandır.

a)

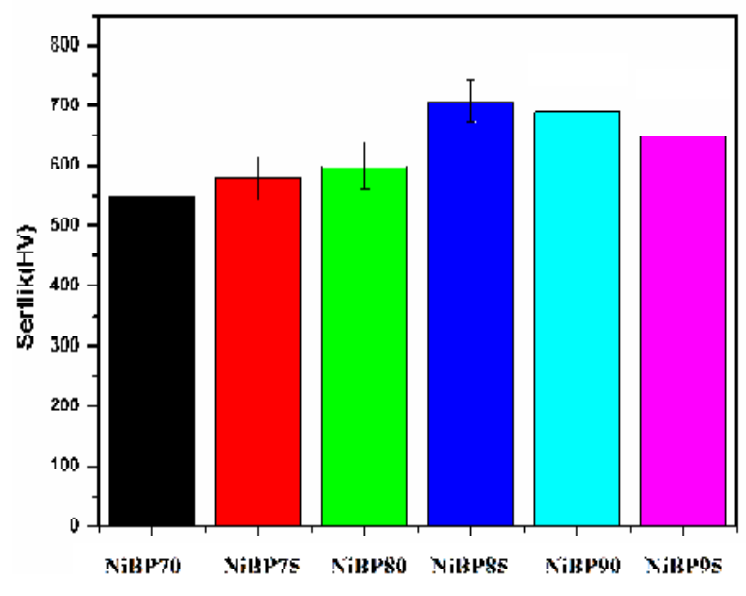

b)

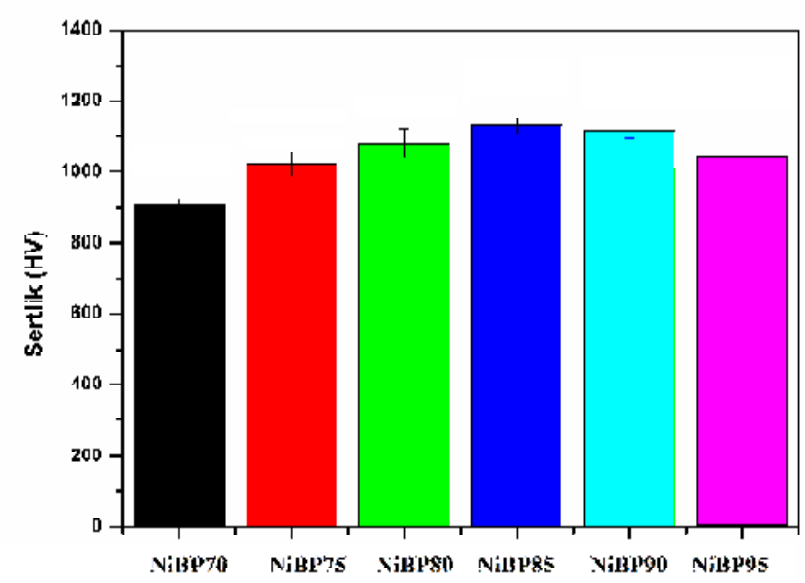

Şekil 4. Akımsız Ni-B-P kaplamaların sertliğine sıcaklığın etkisi (a) 1sıl işlem öncesi (b) 1sıl işlem sonrası

Şekil 5'de Ni-B-P kaplamaların aşınma yüzeylerinin iz genişliği görülmektedir. Sıcaklıkla birlikte iz genişliğinin azaldığ fazlardan kaynaklanmaktadır. $95^{\circ} \mathrm{C}$ 'de izin artmasının sebebi ise yapının değişmesiyle birlikte X-ray de varlığı ispatlanan sülfürlü bir yapının bor ve/veya fosforlu yapıya göre aşınma direncinin düşük olmasından kaynaklanmaktadır. Şekil 6'da ise aşınma numunelerin yüksek büyütmede SEM görüntüleri görülmektedir. Sıcaklık arttıkça mikroçatlaklar azalmaktadır. En fazla mikroçatlak $70^{\circ} \mathrm{C}$ iken deleminasyonun en fazla olduğu kaplama $95^{\circ} \mathrm{C}$ 'dir. 

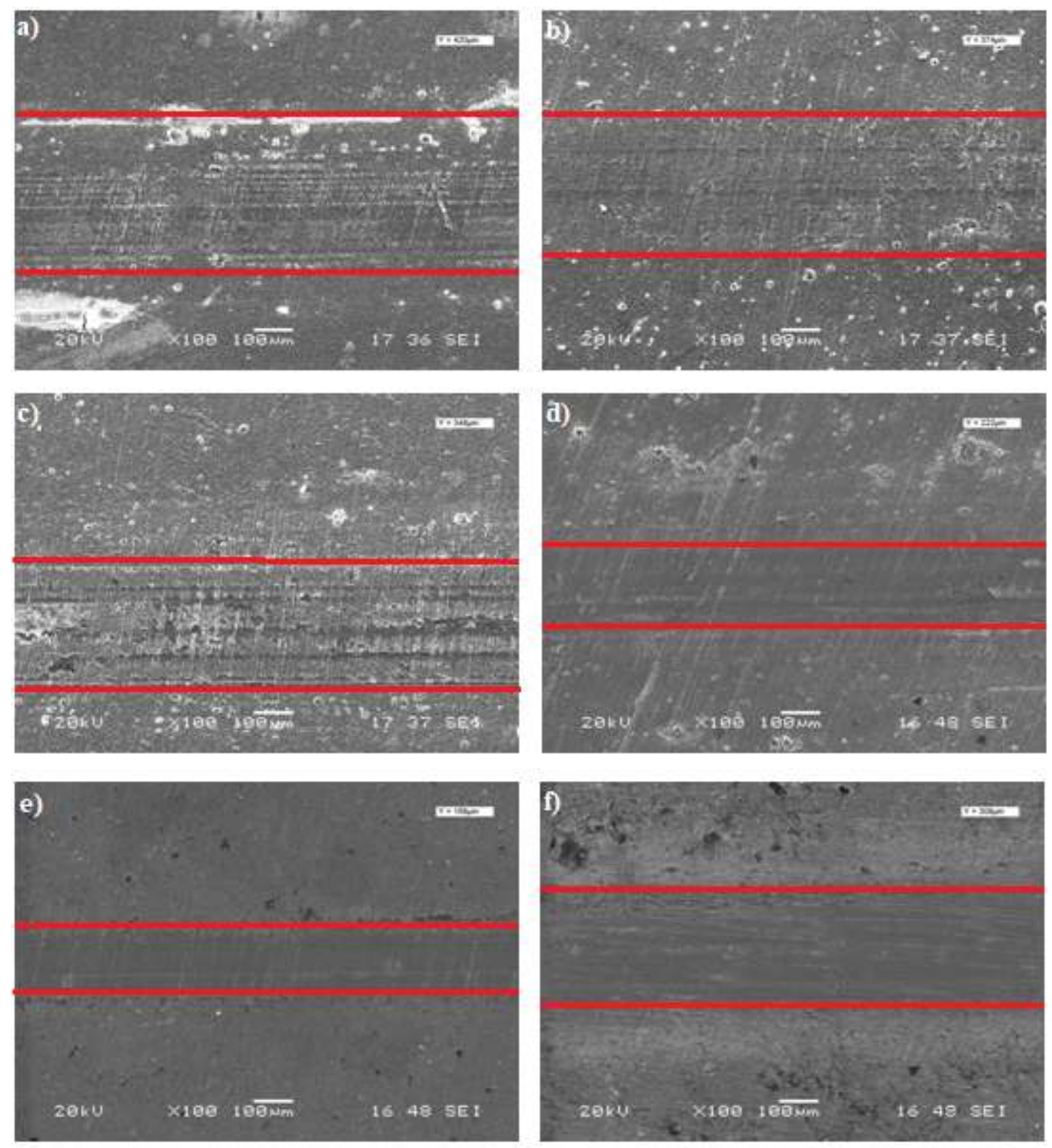

Şekil 5. Akımsız Ni-B-P kaplamaların aşınma iz genişliğinin SEM görüntüsü (a) NiBP70, (b) NiBP75, (c) NiBP80, (d) NiBP85 e) NiBP90 (f) NiBP95

Şekil 6'da aşınma izlerinin yüksek büyütmeli SEM görüntüleri yer almaktadır. Aşınma yüzeyleri incelendiğinde kaplama yüzeyi ile bilye (counterpart) arasında plastik deformasyon meydana geldiği anlaşılmaktadır. Yüzeylerde, plastik deformasyon ile ilişkili mikro çatlaklar ve sonrasında bilye ile kaplama tabakası ara yüzeyinde deleminasyon tipi aşınma mekanizmalarının oluştuğu görülmektedir. Yüksek büyütmeli aşınma yüzeylerinin SEM görüntüleri incelendiğinde, sıcaklık arttıkça plastik deformasyonun daha fazla meydana geldiği ve mikro çatlak oluşumu gözlenmektedir [9]. 

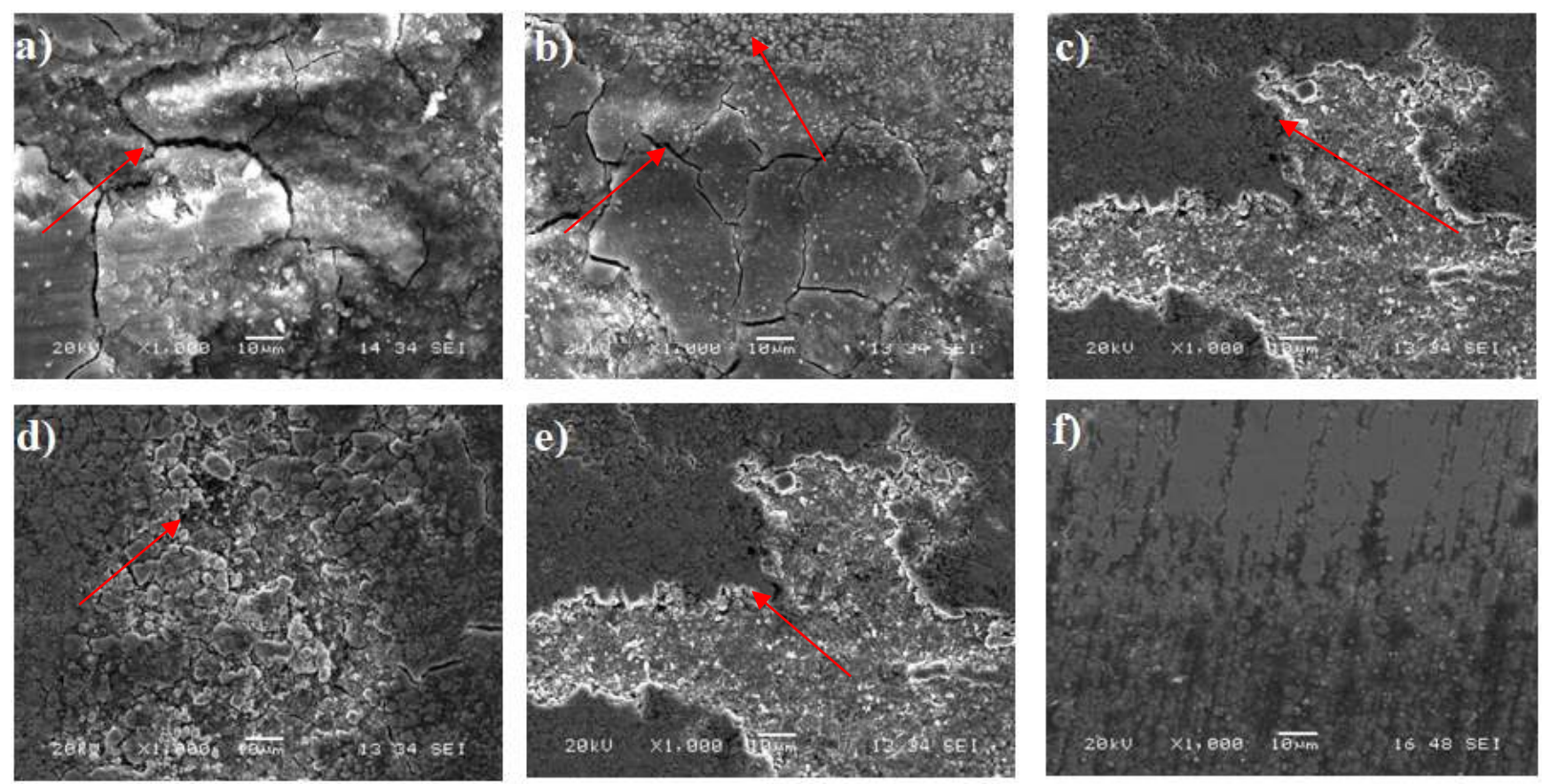

Şekil 6. Akımsız Ni-B-P kaplamaların aşınma 1000X büyütmede SEM görüntüsü (a) NiBP70, (b) NiBP75, (c) NiBP80, (d) NiBP85 e) NiBP90 (f) NiBP95

\section{Sonuçlar}

Akımsız Ni-B-P kaplamalar tek katmanlı olarak başarı ile üretilmiş ve banyo sıcaklığının artmasıyla kaplama kalınlığında artış (95 dereceye kadar) sağlanmıştır. Isıl işılem uygulanmamış numunede amorf yap1 baskınken, 1 sil işlem sonrası $\mathrm{Ni}_{3} \mathrm{P}, \mathrm{Ni}_{2} \mathrm{P}, \mathrm{Ni}_{3} \mathrm{~B}$ ve $\mathrm{Ni}_{2} \mathrm{~B}$ kristalin fazlarının artışına bağlı olarak sertlikte de artış gözlenmiştir. Kaplamada en yüksek sertliğe $85-90{ }^{\circ} \mathrm{C}^{\prime}$ lik sıcaklıklarda ulaşılmış olup, 1sıl işlem sonrası yaklaşık 1200 Vikers sertliklere ulaşılmıştır. Bu değerin sert krom kaplamaların sertliği göz önüne alındığında oldukça yüksek ve önemli olduğu sonucu da ortaya konmuştur.

\section{Teşekkür}

Bu çalışma, Tübitak’ın 1005 çerçevesinde desteklediği 116M998 Nolu proje sonuçlarından hazırlanmıştır.

\section{Kaynaklar}

[1] A. Brenner and G. E. Riddell, "Nickel plating on steel by chemical reduction," J. Res. Natl. Bur. Stand. (1934)., vol. 37, no. 1, p. 31, 1946. 
[2] R. C. Agarwala and V. Agarwala, "Electroless alloy / composite coatings : A review," Sadhana, vol. 28, no. August, pp. 475-493, 2003.

[3] J. B. Mallory, Gleen o.; Hajdu, 'Electroless Plating: Fundamentals and Applications, 1st editio. American Electroplaters and Surface Finishers Society, 1990.

[4] P. Sahoo and S. K. Das, "Tribology of electroless nickel coatings - A review," Mater. Des., vol. 32, no. 4, pp. 1760-1775, 2011.

[5] A. Yli-Pentti, "Electroplating and Electroless Plating," in Comprehensive Materials Processing, 2014.

[6] J. Sudagar, J. Lian, and W. Sha, "Electroless nickel, alloy, composite and nano coatings - A critical review," Journal of Alloys and Compounds, vol. 571. pp. 183-204, 2013.

[7] V. Vitry and L. Bonin, "Formation and characterization of multilayers borohydride and hypophosphite reduced electroless nickel deposits," Electrochim. Acta, 2017.

[8] Y. Wang, C. Xiao, and Z. Deng, "Structure and corrosion resistance of electroless Ni-Cu-P," Plat. Surf. Finish., vol. 79, no. 3, pp. 57-59, 1992.

[9] P.G. Venkatakrishnan, S. S. M. Nazirudeen, T.S.N. S. Narayanan, 'Formation and Structural Characterization of Electroless Ni-B-P Ternary Alloy Coatings" Applied Mechanics and Materials 592-594 385-390 (2014).

[10] J. I. G. T. Xiang, W. H. Huang, ' Deposition and Characterization of Electroless NickelPhosphorus-Boron Coatings From Acidic Bath', Electrochemictry, 61 (2000).

[11] S. Jian, Z.Qi, S. Sun, Y. Zeng, Z. Liu, Y. Liu, L. Song, G. Ma, 'Design and fabrication of superhydrophobic/ superoleophilic $\mathrm{Ni}_{3} \mathrm{~S}_{2}$-nanorods/Ni-mesh for oil-water separation", Surface and Coatings Technology, 337 370-378 (2018).

[12] P. Sun, T.Huang, Z. Chen, L. Tian, H. Huang, N. Huang, S. Zhou, M. Long, Y. Sun, X. Sun," Solution Processed NixSy Films: Composition, Morphology and Crystallinity Tuning via Ni/S-Ratio-Control and Application in Dye-Sensitized Solar Cells", Electrochimica Acta, 246 285-293 (2017).

[13] K. Zhang, J. Li, W. Liu, J. Liu, C. Yan, 'Electrocatalytic activity and electrochemical stability of $\mathrm{Ni}-\mathrm{S} / \mathrm{CeO} 2$ composite electrode for hydrogen evolution in alkaline water electrolysis", International Journal of Hydrogen Energy, 41 22643-22651 (2016). 